\title{
Pectinate Line
}

National Cancer Institute

\section{Source}

National Cancer Institute. Pectinate Line. NCI Thesaurus. Code C34245.

An anatomical line of demarcation that separates the upper and lower part of the anal canal, both in structure and neurovascular supply, reflecting the different embryologic origin; superior to the line the epithelium is a mucous membrane like the rest of the gastrointestinal tract and inferiorly the epithelium is considered cutaneous, and is composed of stratified squamous keratinized with hair and sebaceous glands. 